\title{
O TEXTO: ELEMENTO ARTICULADOR ENTRE O ADOLESCENTE E A CIDADANIA
}

\author{
Esmeri Malagute Pereira (G-UEL)
}

Regina Maria Gregório (orientadora)

\section{RESUMO}

O projeto de Extensão: "O texto elemento articulador entre o adolescente e a cidadania", tem sido aplicado no Centro da Juventude, em Cambé e tem como objetivo levar o graduando (UEL), às experiências reais da sala de aula. Além disso, visa a formação do cidadão crítico, por meio do trabalho com a leitura e a escrita, tendo como veículo, o jornal impresso. A turma trabalhada no ano de 2015, abarcou alunos do ensino fundamental, que frequentaram a escola pública do sexto ao nono ano. Houve, por meio de reuniões semanais, apoio das disciplinas de Metodologia e Prática de Ensino e Linguística Aplicada, para que ocorresse, da melhor forma possível, a transposição da teoria vivenciada na academia para a prática da escola. O trabalho com a extensão, permite um elo entre universidade x escola, de suma importância para a formação do futuro discente, pois permite que o aluno aplique os conhecimentos adquiridos, proporcionando uma vivência integral para uma licenciatura plena.

Palavras-chaves: adolescente, cidadania, prática

\section{CONSIDERAÇÕES INICIAIS}

Neste artigo, pretendemos analisar como a relação teoria e prática, contribuem para a formação do futuro professor de Língua Portuguesa. Como laboratório de prática discente e docente no ano de 2015, tivemos o Centro da Juventude de Cambé, formada por alunos do sexto ao nono ano, turmas heterogêneas, algo que inicialmente nos preocupou, mas que, no decorrer do ano, conseguimos resolver.

As regências tiveram início embasadas em reuniões semanais, ministradas pelos docentes orientadores da Universidade Estadual de Londrina.

\subsection{Fundamentação teórica}

Um dos objetivos do projeto foi o trabalho com os jornais e os gêneros que ali circulam. Desse modo, os gêneros textuais que compõem o jornal (carta do leitor, notícia, classificados, reportagens, artigos de opiniões, charges, entre outros), abrem um leque de possibilidades para o ensino de Língua Portuguesa contextualizado, capaz de abarcar em apenas um veículo de comunicação, gêneros que desenvolvam a argumentação, criticidade, tanto no texto escrito, quanto na oralidade.

Apesar de constar no planejamento inicial a ideia de levar aos alunos a maioria dos gêneros do jornal, isso não se concretizou, devido a greve das universidades em 2015 e o ajuste do calendário letivo, permitindo que trabalhássemos apenas com as charges

e as cartas do leitor. 


\title{
XI SEMINÁRIO DE PESQUISA EM CIÊNCIAS HUMANAS - SEPECH \\ Humanidades, Estado e desafios didático-científicos \\ Londrina, 27 a 29 de julho de 2016
}

Amparados também pela disciplina de metodologia, tivemos acesso ao texto Cartas do leitor; ação retórica no Ensino fundamental, de Carvalho (2008), que inicialmente nos traz a proposta dos PCNs (1998) e tem como base trabalhar a linguagem como função social.

A autora esclarece-nos que, para trabalhar a competência discursiva do aluno é necessário que os professores levem para a sala de aula, textos que sejam próximos dos alunos no seu cotidiano, para que façam um trabalho contextualizado.

Desta forma, a exploração dos gêneros presentes no jornal, concentraram-se no trabalho com as cartas do leitor e a charge, textos estes que levaram o aluno a desenvolver sua criticidade, tão importante para a formação do aluno. Neste sentido, a proposta avança e procura apresentar aos alunos o conteúdo do texto, o contexto social em que ele circula, as marcas linguístico- enunciativas dos gêneros estudados e, por fim, a elaboração de textos pelos alunos, trazendo, desta forma, para a sala de aula, ideias, argumentos variados, enriquecendo as leituras e afastando-se do ensino tradicional, que na maioria das vezes, contempla somente os textos da esfera escolar.

Carvalho (2008), traz algumas marcas textuais que compõem a carta do leitor que foram trabalhadas em sala como, o destinatário, a intencionalidade de quem escreve a qual poderá ser, uma reclamação, um elogio, uma sugestão, um comentário sobre algum fato relatado pelo próprio veículo de comunicação.

Dentro do arcabouço de disciplinas acadêmicas que nos ampara, temos ainda como suplemento a Linguística Aplicada (LA), pois entendemos que esta ciência estuda fenômenos linguísticos dentro da esfera escolar e visa desvendá-los com intuito de aprimorar o fazer pedagógico do professor. Como ressalta Celani,

\begin{abstract}
"A LA como área de conhecimento é vista hoje como articuladora de múltiplos domínios do saber, em diálogo constante com vários campos que têm preocupação com a linguagem. Tendo em vista que a linguagem permeia todos os setores de nossa vida social, política, educacional e econômica, uma vez que é construída pelo contexto social e desempenha o papel instrumental na construção dos contextos sociais nos quais vivemos, está implícita a importância da LA no equacionamento de problemas de ordem educacional, social, política e até econômica." (CELANI, 2000:19/20, Apud, SOARES 2008).
\end{abstract}

Para um trabalho completo, precisamos levar em consideração a importância e adequação da linguagem, do discurso oral e do texto escrito, pois o alunado ali presente tem como objetivo maior seu primeiro emprego. O discente da UEL é um mediador, que tem como missão ajudar na aquisição das necessidades reais do falante de língua portuguesa, dando instrumentos necessários que estimulem sua criticidade.

Gnerre (1994), explicita que a língua serve como um instrumento de interação para as pessoas falarem e serem ouvidas, para serem respeitadas e exercerem influências em ambientes onde realizam atos linguísticos. Deste modo, afirmamos que há três regras para serem seguidas no ato comunicativo, saber quando se fala, o que se fala e para quem se fala. Ao obedecer estas regras, há maior facilidade de ocorrer a interação social entre falante e ouvinte.

1. Este trabalho integra o projeto de extensão "O texto elemento articulador entre o adolescente e a cidadania”, coordenado pela professora Dra. Regina Maria Gregório. 


\section{SEMINÁRIO DE PESQUISA EM CIÊNCIAS HUMANAS - SEPECH \\ Humanidades, Estado e desafios didático-científicos \\ Londrina, 27 a 29 de julho de 2016}

"A começar do nível mais elementar de relações com o poder, a linguagem constitui o arame farpado mais poderoso para bloquear o acesso ao poder". (GNERRE, p. 22).

A interação social por meio da língua caracteriza-se, fundamentalmente, pela argumentação. Como dotado de razão e vontade, o homem, constantemente, avalia, julga, critica, isto é, forma juízos de valor. Por outro lado, por intermédio do discurso, ação verbal dotada de intencionalidade, tenta influir sobre o comportamento do outro. Por esse motivo, pode-se afirmar que o ato de argumentar constitui o ato linguístico fundamental, pois todo e qualquer discurso possui uma ideologia. Na sequência, segue a análise de duas charges, como exemplificação do trabalho desenvolvido no projeto.

\section{ANÁLISE}

\subsection{Trabalho com Charges}

As charges escolhidas foram do cartunista Walmir Orlandeli, colhidas em seu blog www.ultimaquimera.com.br e www.orlandeli.com.br. O artista faz um rompimento dos padrões tradicionais com temáticas atuais em suas obras. Para uma leitura completa, porém sucinta do gênero, contamos com "A leitura dos quadrinhos" de Paulo Ramos.

Contemplando a linguagem verbal e não verbal, as charges, na maioria das vezes, apresentam como característica, o exagero e a ironia, sempre com temais atuais.

Para início do trabalho com o gênero charge, levamos os jornais impressos JL (Jornal de Londrina), no entanto, se fez necessário diante dos alunos, algo que os instigassem com assuntos mais polêmicos para aqueles adolescentes.

A primeira charge foi a mais instigante, onde pudemos analisar e incentivar a argumentação pela oralidade, pois a concepção de família é algo muito particular.

O aluno Erik, nos disse a seguinte frase: Pra mim, se não tiver pai e mãe não é família". E logo o aluno Jhonatan, rebateu: "Então, eu minha irmã e minha mãe somos o quê?".

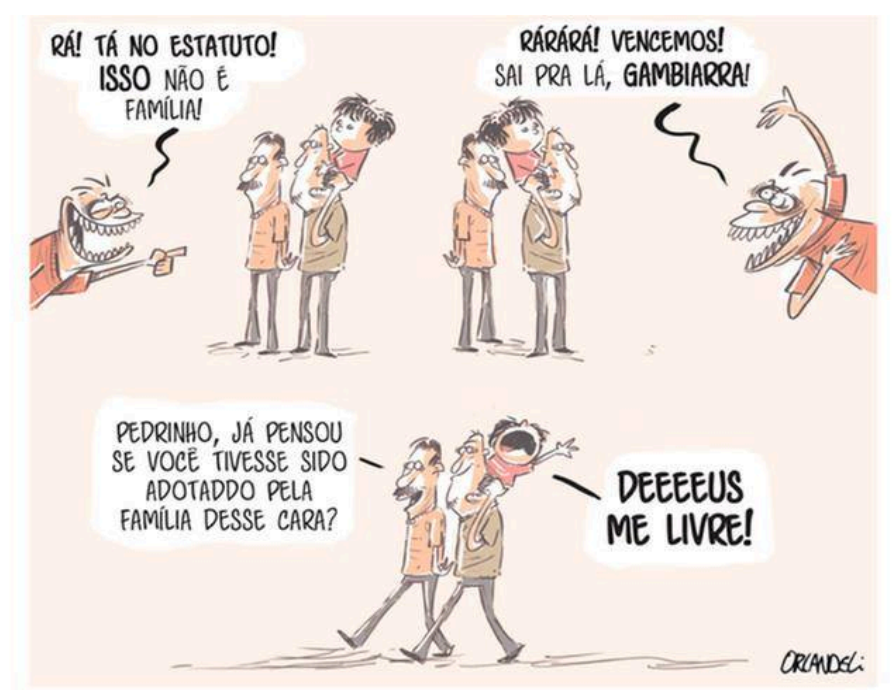

1. Este trabalho integra o projeto de extensão "O texto elemento articulador entre o adolescente e a cidadania”, coordenado pela professora Dra. Regina Maria Gregório. 


\section{SEMINÁRIO DE PESQUISA EM CIÊNCIAS HUMANAS - SEPECH \\ Humanidades, Estado e desafios didático-científicos \\ Londrina, 27 a 29 de julho de 2016}

Fonte: disponível em <http://www.orlandeli.com.br>, acesso em novembro de 2015.

As discussões foram muito válidas quanto aos posicionamentos argumentativos e respeitosos aos que ali pensavam de maneira distinta um do outro. Logo, o trabalho com a linguagem verbal e não verbal, mostra ao aluno, quantas possibilidades temos de comunicação, pois se o rabicho indica a fala, o exagero da boca do personagem que critica aquela família serve para mostrar o quanto o preconceito é desnecessário e inconveniente.

Na segunda charge, (escolhida dentre muitas outras) levamos o assunto "Rave" pois, por nossas aulas serem às segundas-feiras, muitos dos alunos vinham comentando a frequência em tais festas. Quando mostramos esta charge a maioria da turma não compreendia, então fomos dando pistas para que chegassem a uma leitura.

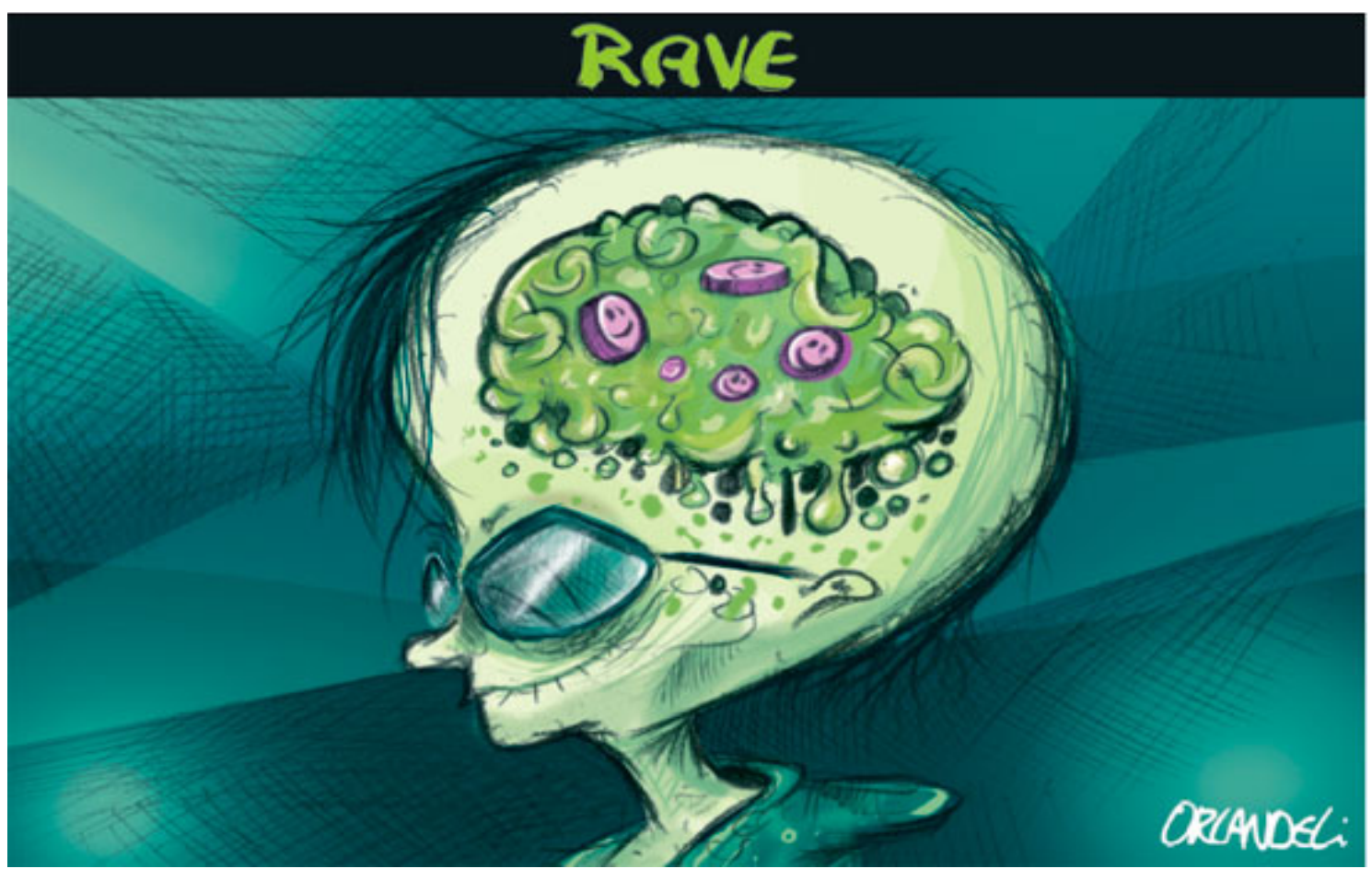

Fonte: disponível em <www.ultimaquimera.com.br, acesso setembro de 2015.

A primeira pergunta feita foi; O que é "rave"? O que a maioria da população pensa dessas festas? E o uso de drogas tem consequências?

A partir daí, os alunos foram decifrando a linguagem não verbal e fazendo vários apontamentos sobre o uso de drogas, a liberação da maconha, a droga e as consequências danosas ao intelectual do adolescente, dentre outros.

Nesta terceira charge, trabalhamos a ideologia implícita em contexto político. Para tanto, um assunto sempre atual, a relação da presidenta Dilma Rousseff e o povo. A leitura não verbal desta vez ficou um pouco mais explícita, pela caricatura da Presidenta como: o exagero dos dentes, e a faixa verde e amarela, cores que representam a bandeira do Brasil.

Contudo, na segunda vinheta, os alunos ficaram em dúvida com relação à semelhança do personagem com o ex presidente Lula, caracterizado pela barba.

1. Este trabalho integra o projeto de extensão "O texto elemento articulador entre o adolescente e a cidadania”, coordenado pela professora Dra. Regina Maria Gregório. 


\section{SEMINÁRIO DE PESQUISA EM CIÊNCIAS HUMANAS - SEPECH \\ Humanidades, Estado e desafios didático-científicos \\ Londrina, 27 a 29 de julho de 2016}
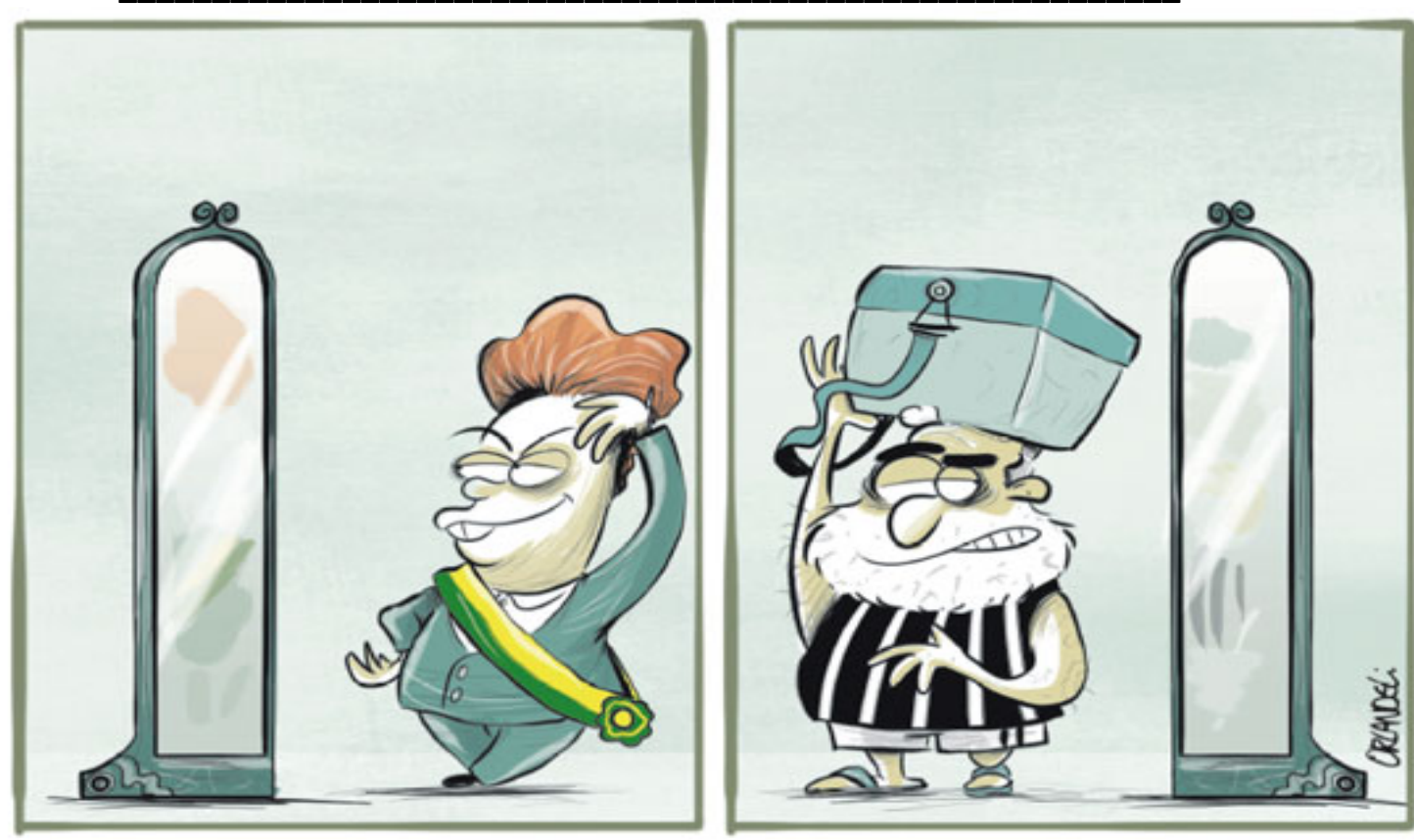

Fonte: disponível em <http://www.orlandeli.com.br>, acesso novembro de 2015.

Logo, como mediadores do conhecimento, começamos mostrar as diferenças entre os personagens e possíveis leituras como; as vestimentas, a pose, a caixa térmica na cabeça do personagem da segunda vinheta, indicando o trabalho braçal ou árduo, enquanto a presidenta supostamente se envaidece, pela melhoria de aparência, após os tratamentos de beleza, que ocorreram após ser eleita.

Para finalizar este tema pedimos produções e elencamos algumas para evidenciar a aprendizagem.

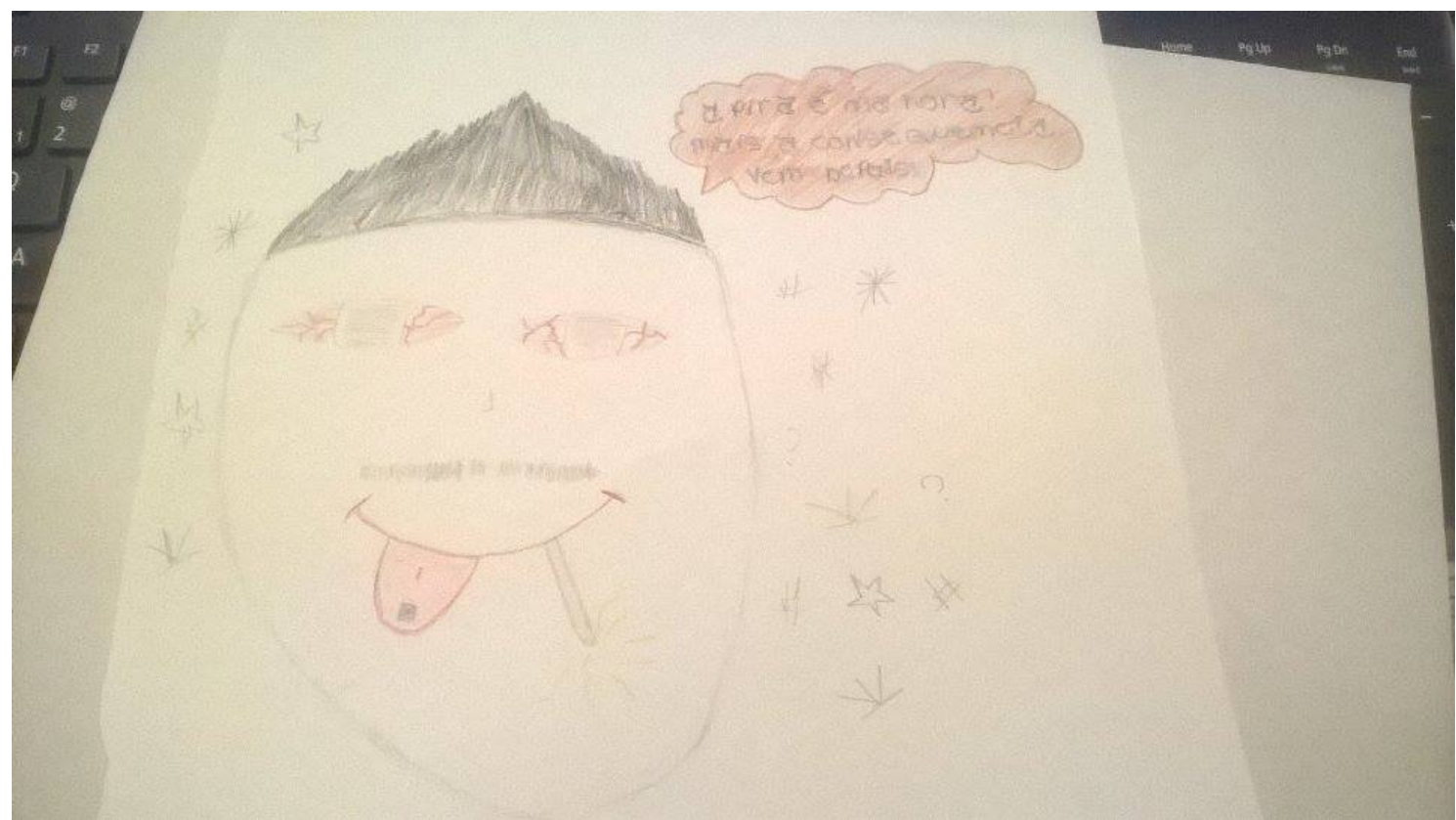

Charge produzida pelo aluno Jorge, no Centro da Juventude de Cambé, ano de 2015.

1. Este trabalho integra o projeto de extensão "O texto elemento articulador entre o adolescente e a cidadania", coordenado pela professora Dra. Regina Maria Gregório. 


\section{SEMINÁRIO DE PESQUISA EM CIÊNCIAS HUMANAS - SEPECH \\ Humanidades, Estado e desafios didático-científicos \\ Londrina, 27 a 29 de julho de 2016}

Como pudemos perceber, o aluno entendeu que as marcas textuais que a charge de número dois, apresenta é o exagero (marcado pelo tamanho do desenho, e a vermelhidão nos olhos), além do balão de fala, que transmite a reflexão que este produtor textual obteve, depois de muitas discussões entre os alunos e as professorasestagiárias. A fala do balão diz:" A pira é na hora mas a consequência vem depois".

Para que as produções tivessem leitores reais, optamos por fazer um mural para que todos que frequentassem o Centro pudessem ler. Por esse motivo, não temos todas as produções.

\subsection{Carta do Leitor}

Elucidados por Carvalho (2008), levamos para a sala de aula talões de luz para uma primeira leitura. Os alunos, num primeiro momento, disseram que aquilo não seria um texto. Fomos lendo desde o nome do cliente, até os últimos indícios de informação que ali continham. Nosso objetivo era questioná-los sobre o uso da palavra "contribuição" e refletir se teria o mesmo significado da palavra "taxa".

Antes de uma definição concreta desses dois termos, deixamos fluir a discussão, sobre os serviços prestados pela empresa de iluminação. Vários relatos foram aparecendo, e ampliou-se para serviços prestados por outras empresas como: telefônico, médico, saneamento, dentre outros. Foram colocadas no quadro negro as definições dos dois termos, segundo dicionário Houassis.

Para fomentar a discussão, levamos vídeos que divergiam de opiniões do que se era "taxa" e "contribuição", com relatos argumentativos de prefeitos e vereadores, dentre outros.

Com estes encaminhamentos, demonstramos as marcas linguísticas e os argumentos que deverão conter uma carta do leitor, propusemos que os alunos elaborassem uma carta do leitor, que tivesse como temática a iluminação pública com possíveis soluções para seu bairro, ou uma carta do leitor que elogiasse a iluminação pública e os serviços prestados pela companhia elétrica para sua comunidade.

Apresentamos abaixo, a primeira versão de uma carta do leitor produzida pelo aluno Bruno, a produção final do aluno, depois de corrigida coletivamente, foi exposta no mural do Centro da Juventude, por esse motivo não a temos em mãos.

1. Este trabalho integra o projeto de extensão "O texto elemento articulador entre o adolescente e a cidadania", coordenado pela professora Dra. Regina Maria Gregório. 


\section{SEMINÁRIO DE PESQUISA EM CIÊNCIAS HUMANAS - SEPECH \\ Humanidades, Estado e desafios didático-científicos \\ Londrina, 27 a 29 de julho de 2016}

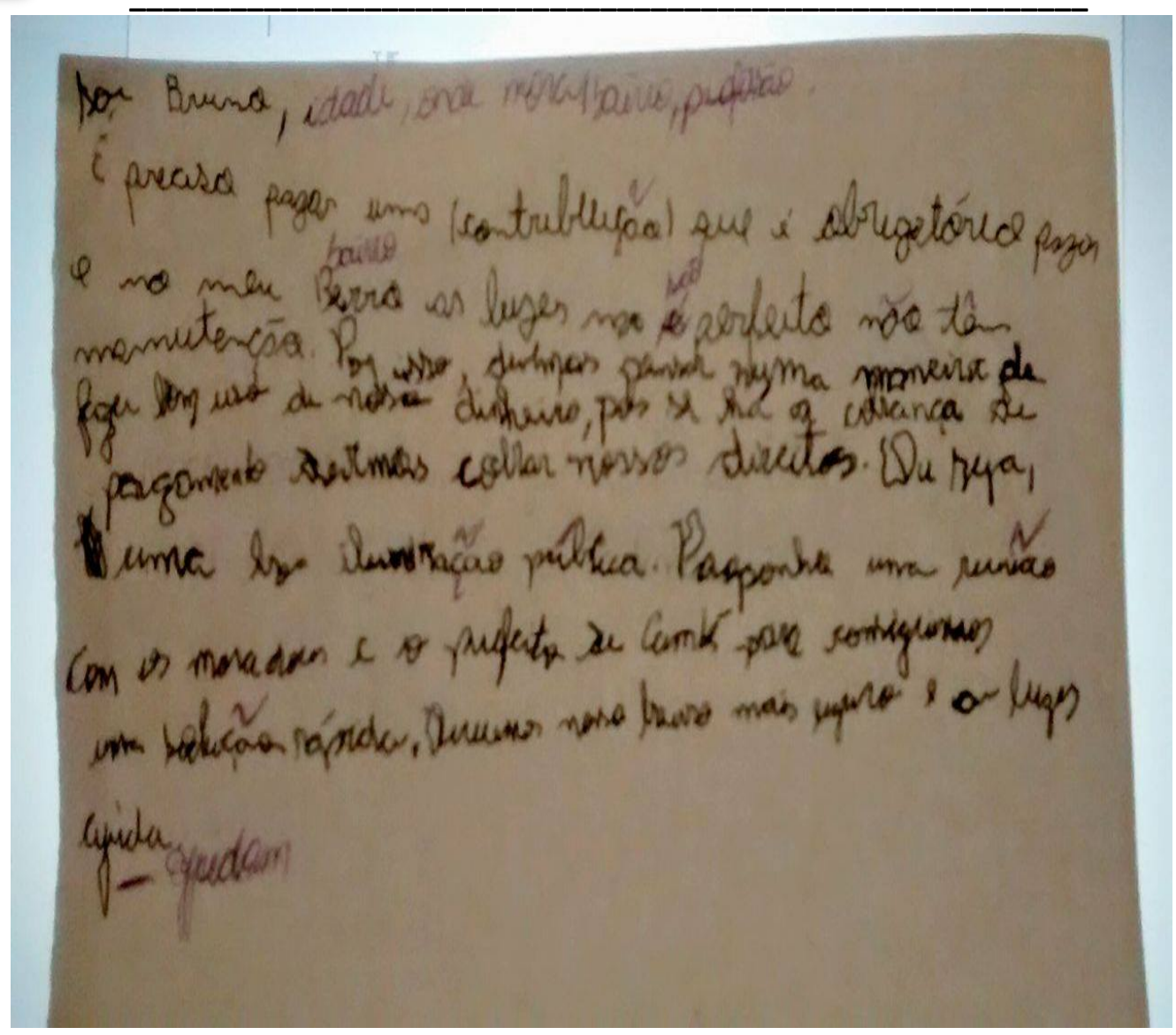

Evidencia-se que, alguns ajustes foram feitos como: acento, pontuação e concordância gramatical, porém nosso objetivo maior foi a argumentação. Podemos averiguar que o produtor textual conseguiu expor suas ideias quando ele escreve "no meu bairro as luzes não é perfeito não tem manutenção. Por isso, devemos pensar numa maneira de fazer bom uso do nosso dinheiro, pois se há cobrança de pagamento devemos cobrar nossos direitos". Nesse trecho o aluno repensa a situação de iluminação pública do bairro e os serviços prestados pela companhia elétrica, visa procurar seus direitos de cidadão contribuinte.

No último parágrafo, Bruno termina dizendo "Proponho uma reunião com os moradores e prefeito de Cambé para conseguirmos uma solução rápida". Nesse sentido entendemos que, o aluno além de argumentar, consegue propor uma possível solução para um bem geral, da sua comunidade.

Assim, conseguimos por meio da interação nosso objetivo maior, ensinar a adequação da linguagem, usar a língua para conseguir o que se pretende, ou seja, mostrar ao nosso alunado que dominando plenamente a Língua Portuguesa, todos serão capazes de conseguir seus objetivos.

\section{CONSIDERAÇÕES FINAIS}

De acordo com GERALDI (2011), o ensino de Língua Portuguesa precisa fugir da artificialidade, ou seja, é preciso que se vá além da leitura meramente por decodificação. Para tanto, é preciso que o ensino de língua materna, seja de caráter do diálogo (língua + linguagem), e não de um monólogo.

1. Este trabalho integra o projeto de extensão "O texto elemento articulador entre $o$ adolescente e a cidadania”, coordenado pela professora Dra. Regina Maria Gregório. 


\title{
XI SEMINÁRIO DE PESQUISA EM CIÊNCIAS HUMANAS - SEPECH \\ Humanidades, Estado e desafios didático-científicos \\ Londrina, 27 a 29 de julho de 2016
}

"Na prática escolar, institui-se uma atividade linguística artificial: assumem-se papel de locutor/interlocutor durante o processo, mas não se é locutor/interlocutor efetivamente. Essa artificialidade torna essa relação intersubjetiva ineficaz, porque a simula. (GERALDI, p.89, 2011).

Portanto, o professor instituído mediador do conhecimento é o elo entre o aluno e o texto. O ensino de Língua Portuguesa no projeto de extensão, foge positivamente desses padrões de artificialidade, pois leva ao aluno textos próximos de seu cotidiano. E ainda, tem como contribuição para esse ensino (docente) e aprendizado (discente) a teoria aliada a prática.

Em suma, o professor em formação, deve posicionar-se de maneira crítica e reflexivamente diante do seu conhecimento, e diante de problemas que surgem em meio ao percurso de educador, deve trilhar seu próprio conhecimento, ou seja, desprender-se da artificialidade.

\begin{abstract}
"Dessa forma, a formação de professores pode alcançar outras dimensões no sentido de se produzir um conhecimento que dote os futuros professores e professoras das noções (OLIVEIRA, 2003, p.73) "sobre o ensino da língua como prática discursiva, de natureza social, sem dispensar o domínio de sua organização estrutural, mas que compreenda os elementos que a organizam enquanto recursos para expressar pontos de vista", seja discordando, concordando, ocultando valores, desvendando mitos. Ou seja, a formação do professor de língua materna deve-se orientar para a compreensão da língua em sua complexidade”. (BENEVIDES, p.4, 2006).
\end{abstract}

Por fim, podemos afirmar que a experiência com a docência no Centro da Juventude de Cambé, foi uma prática real, que nos proporcionou uma certeza, de que a formação de professores não pode ser vista de forma estanque, pois o docente deve estar atento ao sujeito que ele está formando, sua trajetória de vida, além de preocupar-se com seu futuro profissional.

Concluímos que, para o fazer pedagógico, deve-se levar sempre em conta, aspectos sócio-histórico-culturais, o contexto social, as condições materiais e de tempo, para que possamos formar sujeitos, que lutem por sua cidadania, capazes de argumentar, pensar e refletir sobre qualquer temática. Em suma, o ensino de Língua Portuguesa realizado de maneira eficaz, é um instrumento poderoso para a formação do cidadão.

\section{REFERÊNCIAS}

BAKHTIN, Mikhail M. Os gêneros do discurso. In: . Estética da criação verbal, São Paulo: Martins Fontes, 2000.

BENEVIDES, A. S. A formação de professores do curso de letras - aspectos para uma prática reflexiva. Revista letra magna, divulgação eletrônica, n. 05, p. $1-19,2^{\circ}$ semestre de 2006.

1. Este trabalho integra o projeto de extensão "O texto elemento articulador entre o adolescente e a cidadania”, coordenado pela professora Dra. Regina Maria Gregório. 


\section{SEMINÁRIO DE PESQUISA EM CIÊNCIAS HUMANAS - SEPECH \\ Humanidades, Estado e desafios didático-científicos \\ Londrina, 27 a 29 de julho de 2016}

GERALDI, João Wanderley. O texto na sala de aula. In: 2000.

. (Org. ). São Paulo: Ática,

GNERRE, Maurizio. Linguagem, escrita e poder - Linguagem, Poder e Discriminação. São Paulo: Martins Fontes, 1994. p.1-34.

HOUAISS, Antônio. Dicionário Houaiss da Língua Portuguesa. Rio de Janeiro, Ed. Objetiva, 2001.

PETRONI, Maria Rosa. Gêneros do Discurso, leitura e escrita: experiências de sala de aula. In: CARVALHO, de Rodrigues Rosilene. Cartas do Leitor: Ação Retórica no Ensino Fundamental. São Carlos; Pedro \& João Editores/ Cuiabá: Ed UFMT, 2008.

RAMOS, Paulo. A linguagem dos quadrinhos. São Paulo: Contexto, 2010.

SOARES, Doris de A. Introdução à Lingüistica Aplicada e sua utilidade para as pesquisas em sala de aula de língua estrangeira. I Simpósio de Estudos Filológicos e Lingüísticos, promovido pelo CiFEFiL e realizado na FFP(UERJ).

$<$ http://www.orlandeli.com.br>, acesso novembro de 2015.

$<$ http://www.ultimaquimera.com.br, acesso setembro de 2015>.

$<$ https://youtu.be/D6RQSJEftz8<acessado em 16/10/2015>.

$<$ https://youtu.be/gAw8QCGi-Io <acessado em 18/10/2015>. 